\title{
Perfusionists in India: The Unseen COVID-19 Warriors during the Pandemic Crisis
}

\author{
R. Manu, M.Sc., P. Sainath, M.Sc. \\ Department of Perfusion Technology, Manipal College of Health Professions, Manipal Academy of Higher Education, Manipal, India
}

ARTICLE INFO

Received March 29, 2021, Accepted June 4, 2021

Corresponding author

P. Sainath

Tel 91-9060172211, Fax 91-9060172211, E-mail sainath.p@manipal.edu, ORCID https://orcid.org/0000-0002-9919-4444

\section{Dear Editor,}

The world's most extreme health crisis in the last year has been the coronavirus disease 2019 (COVID-19) pandemic, which has affected over 200 countries and spread across 6 continents. By mid-March 2021, the World Health Organization had registered over 124 million cases and 2.7 million deaths worldwide. As one of the worst-affected regions, India has faced a rising trend, reporting more than 11 million active cases and 0.16 million deaths by the middle of March 2021 [1]. As this situation has turned into a tremendous healthcare crisis-heralded by the World Health Organization's declaration on March 11, 2020 that COVID-19 had become a pandemic [2]-cooperation and support from all health care workers are anticipated. Like all other healthcare professionals, perfusionists are also working selflessly to counter this situation.

Perfusion technology was first introduced in 1968 at the All India Institute of Medical Science in New Delhi, and perfusionists are still considered an emerging allied health profession today. Perfusionists are working across India, without any demographic considerations or restrictions, around the clock. Along with surgeons and physicians, perfusionists also play the role of healthcare providers in patient care in cardiac operating rooms and intensive care units (ICUs).

In India, during this pandemic crisis, ICU admission has been required for $10 \%-20 \%$ of all diagnosed cases, and approximately $3 \%-10 \%$ of them need airway control and mechanical ventilation. In certain cases, where even ventilator support fails, extracorporeal membrane oxygenation has been found to be beneficial to tackle such situations, even though the usage of extracorporeal membrane oxygenation in this type of patient is not well understood. However, extracorporeal membrane oxygenation remains a viable treatment choice when all other options have failed. Globally, extracorporeal membrane oxygenation is used as a treatment modality for respiratory support in $63 \%$ of cases, cardiac support in $29 \%$ of cases, and both respiratory and cardiac support in $8 \%$ of cases, according to the Extracorporeal Life Support Organization [3]. The skills needed to operate extracorporeal membrane oxygenation are possessed by qualified personnel known as "frontline fighters", such as physicians, nurses, and perfusionists. We discovered that a perfusionist caring for COVID-19 patients on extracorporeal membrane oxygenation operates between 8 and 12 hours per day on average. According to perfusion technologists, wearing personal protection kits while performing intensive patient care is exhausting. In India, like other frontline warriors, burnout among these professionals has been found to be significantly high [4].

Around the globe, the perfusion profession is well established and recognized by peers. The American Society of Extracorporeal Technology, Society of Clinical Perfusion Scientist United Kingdom, and Extracorporeal Life Support Organization are the major recognized professional bodies that work to uplift the perfusionist fraternity globally. According to Schiess [5], "We should then recognize that as perfusionists, we are in a unique position to advocate for enhanced communication among clinicians and medical professionals." He also added "that during this 
time, I urge you all to connect with your professional peers, to find online forums for sharing your pertinent expertise, and to contribute to educational seminars related to the COVID-19 response [5]." This has motivated perfusionists to be more involved in patient care during this pandemic.

The Indian Society for Extracorporeal Technology is doing its level best to showcase the hard work and dedication shown by perfusionists from India in their clinical practice and patient care during this pandemic on national and international platforms. Despite their incessant work, perfusionists remain unrecognized and unacknowledged in many aspects as part of the healthcare team. We hope that by posting this brief letter, we will be heard by all the major healthcare communities and given opportunities to demonstrate our expertise and abilities. As perfusionists, through this appeal, we pledge to do our best in clinical practice not only during the time of crisis, but also throughout our professional life.

\section{Conflict of interest}

No potential conflict of interest relevant to this article was reported.

\section{ORCID}

P. Sainath: https://orcid.org/0000-0002-9919-4444

R. Manu: https://orcid.org/0000-0002-2081-3135

\section{References}

1. World Health Organization. WHO coronavirus (COVID-19) dashboard-India [Internet]. Geneva: World Health Organization; 2021 [cited 2021 Mar 20]. Available from: https://covid19.who.int/region/ searo/country/in.

2. World Health Organization. WHO Director-General's opening remarks at the media briefing on COVID-19 [Internet]. Geneva: World Health Organization; 2020 [cited 2021 Mar 15]. Available from: https://www.who.int/director-general/speeches/detail/who-directorgeneral-s-opening-remarks-at-the-media-briefing-on-covid-19---11march-2020.

3. Kichloo A, Kumar A, Amir R, et al. Utilization of extracorporeal membrane oxygenation during the COVID-19 pandemic. World $\mathrm{J}$ Crit Care Med 2021;10:1-11.

4. Khasne RW, Dhakulkar BS, Mahajan HC, Kulkarni AP. Burnout among healthcare workers during COVID-19 pandemic in India: results of a questionnaire-based survey. Indian J Crit Care Med 2020; 24:664-71.

5. Schiess JG. Perfusion's role in responding to the COVID-19 pandemic. J Extra Corpor Technol 2020;52:5-6. 